\title{
Evaluation of Solar Energy Efficiency by Composite Index over Four Continents
}

\author{
Kamel HAINE $^{1 *}$, Dagnija BLUMBERGA ${ }^{2}$ \\ ${ }^{1,2}$ Institute of Energy Systems and Environment, Riga Technical University, Azenes iela 12/1, \\ Riga, LV 1048, Latvia
}

\begin{abstract}
This paper aims to provide an evaluation of solar energy efficiency by composite index and to compare the value of solar energy across 19 countries located over four continents: Europe, Africa, America, and Asia. 15 indicators were evaluated for the year of 2019 and grouped into four dimensions: economic, social, technical, and environmental. Analytical Hierarchy Process (AHP) was used to estimate the weight of each indicator, and consistency tests were calculated to evaluate weight efficiency. The obtained results of the SEI reveals that the technical dimension and economic dimension play an important role in the solar energy efficiency of a country. The results indicate potential improvement areas for increasing solar efficiency. SEI can be used as a tool in assessing solar energy potential integration in a country.
\end{abstract}

Keywords - Analytic hierarchy method; composite index; dimensions; indicators; solar energy; sustainable development

\begin{tabular}{|ll|}
\hline Nomenclature & \\
$S E I$ & Solar energy efficiency index \\
$V^{+}{ }_{n}$ & Normalized indicator of a positive impact \\
$V^{-}{ }_{n}$ & Normalized indicator of a negative impact \\
$V_{a c t}$ & Actual value of an indicator \\
$V_{\max }$ & Maximum value of an indicator among the values in the country \\
$V_{\min }$ & Minimum value of an indicator among the values in the country \\
$V_{D}$ & Sub-index of a particular dimension \\
$w_{I}$ & Weight of an indicator \\
$w_{D}$ & Number of indicators in a dimension \\
$n_{I}$ & Number of indicators in a dimension \\
$n_{D}$ & Number of dimensions \\
\hline
\end{tabular}

\section{INTRODUCTION}

The growth of renewable energy (RE) is largely a policy-driven process to improve energy security, protect the climate, and enhance economic development. When choosing energy and

* Corresponding author.

E-mail address: hainekamel@hotmail.fr 
associated technologies for the production, distribution, and use of energy services, countries need to take into account the economic, social, and environmental consequences.

The means to achieve this lie with governance and management. This study will demonstrate a methodology of calculation of solar energy efficiency by composite index [1] that serves as a main indicator to countries for the implementation of solar energy and evaluate it efficiency.

Indicators are widely used as a tool for communicating energy issues to policymakers and the public [2]. A properly designed indicator or set of indicators transforms the basic statistical information to provide a deeper understanding of an issue or dimension and helps develop a clear picture of the whole system [3]. Sustainability-related indicators have been developed since the publication of the Brundtland Report in 1987 [4], and various efforts have been made to capture different aspects.

This paper aims to provide an evaluation of solar energy efficiency by composite index for decision-makers and to compare the value of solar energy across several countries located in different regions of the globe. The composite index methodology is used to construct four sub-indices for each dimension of the solar value index that groups a total of 15 indicators, environmental, economic, technical, and social, and applied for 19 countries: Canada, Latvia, South Africa, Mexico, Turkey, France, USA, Japan, Algeria, Slovenia, Tunisia, Morocco, USA, Japan, India Sweden, Libya, UAE, Benin, Slovenia, Hungary, Spain.

\section{Methodology}

In this research, the Solar Energy Efficiency Index is a composite that allows an evaluation of solar energy value and performance across different countries. SEI is also an essential tool in assessing solar energy potential integration, performance of a country, development, and practical support in mid-and long-term decisions. The construction of the solar energy efficiency index is a complex approach that requires integrating fifteen indicators grouped in four dimensions: environmental, economic, technical, and social [5]. The methodology used in our research (see Fig. 1) is developed using a methodological approach applied in various sustainable development academic studies, scientific research papers [5]-[7], and practices of the composite index used in many recognized world sustainability composite indices report such as: World economic forum, the European Commission, and United Nations. 


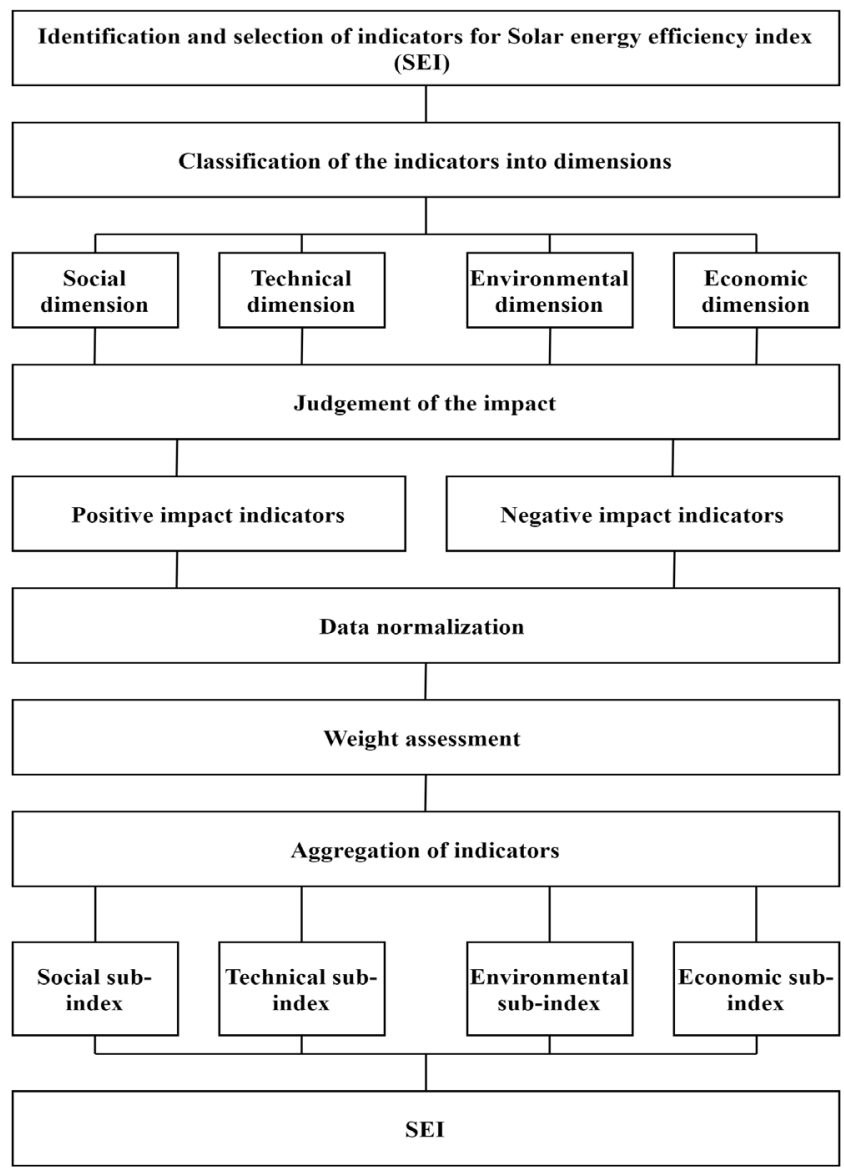

Fig. 1. Methodology of development for Solar Energy Efficiency Index.

\subsection{Data Collection on Selected Indicators}

Indicators allow us to comprehend the dynamic state and better understand the economic, technical, social and environmental systems. Indicators chosen in our study considered the following features: relevancy, accuracy, timeliness, accessibility, and coherence [8], [9]. The data collection was performed for 15 indicators in 19 countries. Data was collected for the year 2019 from different relevant databases: Eurostat, World Bank, Travel \& Tourism Competitiveness Report.

\subsection{Classification of the Indicators}

In this study, the solar energy efficiency index lies on 15 indicators that are divided into four dimensions: Environmental, technical, economic, and social [10] Fig. 2 illustrate the four dimensions and their indicators.

Environmental dimension: The use of energy creates environmental pressure at the city and country levels. Environmental impacts can depend mainly on how energy is produced and used, the amount of GHG produced, and the potential of solar energy generation. The following indicators were used to assess the impact of the environmental dimension: Share 
of electricity production from oil, gas, and coal sources, $\mathrm{CO}_{2}$ emissions, Average yearly direct Irradiation, Share of primary energy from renewable, Greenhouse gas intensity [11].

Economic dimension: The indicators used to identify this dimension are: Electricity Price, research and development expenditure as a share of GDP, Energy consumption. Countries with high economic power and well-developed research and development programs have a higher ability to implement sustainable development and integrate renewable energies at the national level.

Technical dimension: In this study, the technical dimension evaluates the capacity of a country in terms of manufacturing and processing renewable energies; the following indicators are used to determine the influence of the technical dimension in the composite index: PV equivalent area, technicians in research and development, high-technology exports.

Social dimension: reflects the influence of the dimension on the accessibility and ability to develop and integrate renewable energies in society and government efficiency in taking measures to initiate renewable energies [12]. The indicators considered in this study under the social dimension are GDP per inhabitant, population density, government effectiveness, capacity for innovation.

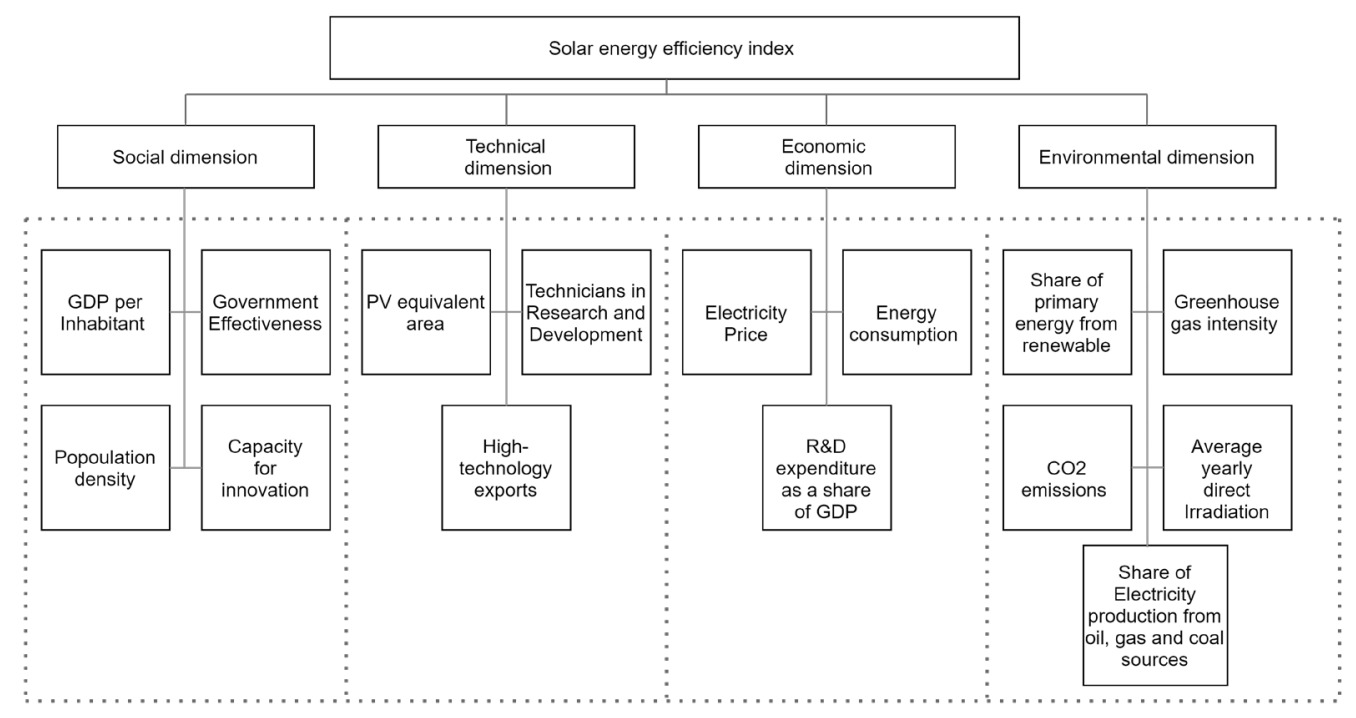

Fig. 2. Solar energy efficiency index structure.

\subsection{Judgement of Indicators}

Once the indicators are grouped into their respective dimension, the next step is to determine the influence of each indicator on the solar energy efficiency index [13].

In our study, the 15 selected indicators were divided into two groups: those with a positive influence, and the second group are indicators that negatively influence the index. Any increase of the positive impact indicator contributes to the increase of the final index ex: Average yearly direct Irradiation. In contrast, an increase of the negative impact indicator contributes to the decrease of the final index ex: share of electricity production from oil, gas, and coal sources in a country. Table1 shows the impact of each indicator. 
TABLE 1. IMPACT OF INDICATORS

\begin{tabular}{|c|c|c|}
\hline Dimensions & Indicator & Impact on SEI \\
\hline \multirow[t]{4}{*}{ Social Dimension } & GDP/inhabitant & + \\
\hline & Density Inhabitants $/ \mathrm{km}^{2}$ & - \\
\hline & Government Effectiveness & + \\
\hline & Capacity for innovation & + \\
\hline \multirow[t]{3}{*}{ Technical } & PV equivalent area \% & - \\
\hline & Technicians in R\&D & + \\
\hline & High technology & + \\
\hline \multirow[t]{5}{*}{ Environmental } & $\begin{array}{l}\% \text { Electricity production from } \\
\text { oil, gas and coal }\end{array}$ & - \\
\hline & $\mathrm{CO}_{2}$ emissions per capita & - \\
\hline & $\begin{array}{l}\text { Average yearly direct Irradiation } \\
\mathrm{kWh} / \mathrm{m}^{2}\end{array}$ & + \\
\hline & $\begin{array}{l}\% \text { Share of primary energy from } \\
\text { renewable }\end{array}$ & + \\
\hline & Greenhouse gas intensity & - \\
\hline \multirow[t]{3}{*}{ Economic } & Electricity Price & - \\
\hline & $\begin{array}{l}\text { R\&D expenditure as a share of } \\
\text { GDP }\end{array}$ & + \\
\hline & Energy consumption & _ \\
\hline
\end{tabular}

\subsection{Data Normalization}

The construction of the solar energy efficiency index involves the aggregation of data with different units of measurement. The data normalization step is important to unify all the units into a standard scale and remove the uncertainty of the indicators. Data normalization allows to compare different indicators to each other and identifies how indicators correlate with index.

There are several methods of normalization: distance-based normalization, ranking, rescaling (min-max transformation), standardization (z-scores).

For the construction of the Solar energy efficiency index, the normalization by the Min-Max method was considered; this method is the simplest and consists of performing linear transformation data while preserving the relationships between the original values; Min-Max method is by far the most widely used method, particularly in the standardization of international indicators such as the Human Development Index [14], [15].

Normalization of indicators by the Min-Max method is given according to the following formula Eq. (1) and Eq. (2): 


$$
\begin{gathered}
V_{U}^{+}=\frac{V_{a c t}-V_{\min }}{V_{\text {max }}-V_{\text {min }}}, \\
V_{U}^{-}=1-\frac{V_{a c t}-V_{\min }}{V_{\text {max }}-V_{\min }},
\end{gathered}
$$

where

$V^{+}{ }_{U} \quad$ Normalized indicator of a positive impact;

$V^{-}{ }_{U} \quad$ Normalized indicator of a negative impact;

$V_{\text {act }} \quad$ Actual value of an indicator;

$V_{\max } \quad$ Maximum value of an indicator among the values in the country.

$V_{\min } \quad$ Minimum value of an indicator among the values in the country.

\subsection{Weight Assessment}

The solar energy efficiency index comprises many indicators, and these variables do not have the same influence on the index. Therefore, the next step after data normalization is the determination of indicator's weight.

The weights reflect the relative importance of each variable; for this, several weighting methods exist such as; statistical models, data envelopment or factor analysis, and unobserved components models or participatory methods like budget allocation processes, analytic hierarchy processes, or equal weights.

Regardless of which method is applied, weights are essentially value judgments. In this study, analytic hierarchy processes (AHP) were used. AHP is a multi-criteria decision-making approach, which has been widely used to solve many comparison problems. The main advantage of AHP is that its hierarchical structure permits to have a better focus on the criteria at each level during weight allocation [16], [17].

In AHP implementation, the pairwise comparison technique prioritizes the alternatives that lead to better goal achievement. For pairwise comparison, an indicator matrix is constructed, which allows us to compare the indicators and assign a number from the standardized comparison scale based on their priority. In this study, the standardized comparison scale used is the original Saaty scale consisting of 9 levels, as shown in Table 2. The weights of the indicators shall be determined separately for each group of indicators (economic, environmental, technical and social). All the components showed a CR value of less than 0.1, signifying that the indicators' weights are consistent.

\begin{tabular}{|c|c|c|}
\hline $\begin{array}{l}\text { Intensity of } \\
\text { importance }\end{array}$ & Definition & Explanation \\
\hline 1 & Equal importance & Two factors contribute equally to the objective \\
\hline 3 & $\begin{array}{l}\text { Somewhat more } \\
\text { important }\end{array}$ & Experience and judgement favour one over the other \\
\hline 5 & $\begin{array}{l}\text { Much more } \\
\text { important }\end{array}$ & Experience and judgement strongly favour one over the other \\
\hline 7 & $\begin{array}{l}\text { Very much more } \\
\text { important }\end{array}$ & $\begin{array}{l}\text { Experience and judgement very strongly favour one over the other. Its } \\
\text { importance is demonstrated in practice. }\end{array}$ \\
\hline 9 & $\begin{array}{l}\text { Absolutely more } \\
\text { important }\end{array}$ & $\begin{array}{l}\text { The evidence favouring one over the other is of the highest possible } \\
\text { validity. }\end{array}$ \\
\hline $2,4,6,8$ & Intermediate values & When compromise is needed. \\
\hline
\end{tabular}

TABLE 2. SAATY'S 1-9 SCALE OF PAIRWISE COMPARISONS [18] 


\subsection{Aggregation of the Indicators}

The calculation of the solar composite index is divided into two parts. The first part calculates the sub-index of each of the four dimensions (environmental, social, technical, and economic) using normalized and weighted indicators using the following Eq. (3).

$$
V_{U}=\sum w \cdot \sum V_{U}^{+}+\sum w \cdot \sum V_{U}^{-}, w_{I}=\frac{1}{n_{I}}
$$

Then, the accumulated sum for each of the four dimensions with their corresponding weight determines the final composite solar energy efficiency index Eq. (4):

$$
S E I=\sum w \cdot \sum V_{D}, w_{D}=\frac{1}{n_{D}},
$$

where

$V_{D} \quad$ Sub-index of a particular dimension;

$w_{I} \quad$ Weight of an indicator;

$w_{D} \quad$ Weight of a dimension;

$n_{I} \quad$ Number of indicators in a dimension;

$n_{D} \quad$ Number of dimensions.

\section{Results}

The solar energy efficiency index (SEI) was calculated to evaluate the solar energy efficiency for 19 countries over four continents; Table 3 shows the dimension sub-index and SEI results for each country.

The index comprises 15 indicators collected for the year 2019 and grouped into four dimensions (Economic, environmental, technical, and social); each dimension provides information and data that allows the comparison of their impact on the overall index.

TABLE 3. SEI AND DimENSIONS SUB-INDEX RESUlTS

\begin{tabular}{llllll}
\hline & $\begin{array}{l}\text { Social } \\
\text { Dimension } \\
\text { sub-Index }\end{array}$ & $\begin{array}{l}\text { Technical } \\
\text { Dimension } \\
\text { sub-Index }\end{array}$ & $\begin{array}{l}\text { Economic } \\
\text { dimension } \\
\text { sub-Index }\end{array}$ & $\begin{array}{l}\text { Environmental } \\
\text { dimension sub- } \\
\text { Index }\end{array}$ & SEI \\
\hline Sweden & 0.96 & 0.47 & 0.89 & 0.49 & 0.70 \\
USA & 0.96 & 0.74 & 0.7 & 0.4 & 0.70 \\
Canada & 0.85 & 0.8 & 0.46 & 0.42 & 0.64 \\
France & 0.8 & 0.68 & 0.63 & 0.4 & 0.63 \\
Spain & 0.62 & 0.65 & 0.32 & 0.56 & 0.54 \\
UAE & 0.76 & 0.5 & 0.39 & 0.38 & 0.51 \\
South & 0.54 & 0.6 & 0.32 & 0.53 & 0.50 \\
Africa & 0.66 & 0.59 & 0.46 & 0.24 & 0.49 \\
Slovenia & 0.83 & 0.16 & 0.79 & 0.17 & 0.49 \\
Japan & 0.41 & 0.71 & 0.21 & 0.59 & 0.48 \\
Mexico & 0.45 & & \\
\hline
\end{tabular}




\begin{tabular}{llllll}
\hline Morocco & 0.35 & 0.61 & 0.34 & 0.6 & 0.48 \\
Turkey & 0.41 & 0.58 & 0.42 & 0.48 & 0.48 \\
Latvia & 0.62 & 0.66 & 0.32 & 0.27 & 0.47 \\
India & 0.42 & 0.61 & 0.28 & 0.5 & 0.45 \\
Algeria & 0.27 & 0.59 & 0.38 & 0.55 & 0.45 \\
Tunisia & 0.35 & 0.62 & 0.35 & 0.45 & 0.44 \\
Hungary & 0.43 & 0.62 & 0.46 & 0.19 & 0.42 \\
Libya & 0.05 & 0.59 & 0.19 & 0.54 & 0.34 \\
Benin & 0.44 & 0.59 & 0.14 & 0.19 & 0.34 \\
\hline Average & 0.56 & 0.6 & 0.42 & 0.41 & 0.50 \\
\hline
\end{tabular}

Table 3 results reveal the SEI for each of the selected countries with an average score of (0.5); we can observe that the technical and social dimensions are the most important factors with the highest contribution to the $S E I$ with an average score of 0.6 and 0.56 , taking into consideration that 1 is the maximum value of the index and 0 is the minimum value.

On the one hand, the results of developed countries show the highest value of the index with a maximum value of 0.70 for Sweden and the USA, followed by Canada 0.64, France 0.63 . On the other hand, countries with the lowest values are Mexico, Morocco, Turkey scoring 0.48 .

The minimum SEI value is reached by Tunisia 0.44 , Hungary 0.42 , Libya 0.34 , and Benin 0.34.

Countries with the lowest and minimum values are mostly emerging countries; on the contrary, developed countries scored the highest value (see Fig. 3); the pattern suggests a strong correlation between the countries' development and the SEI index.

Solar Energy Efficiency Index

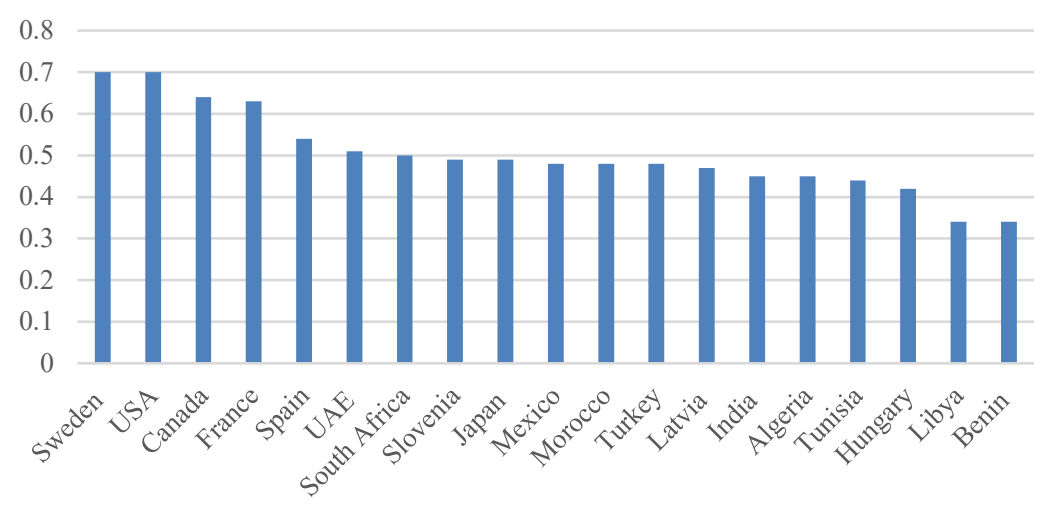

Fig. 3. Solar energy efficiency index for the evaluated countries.

\subsection{Results of the Social Dimension Sub-Index}

From Fig. 4(a) the countries showing the best results are Sweden and USA, with the highest value of the social sub-index 0.96 , as those countries have a high capacity for innovation and 
$2021 / 25$

Government Effectiveness. In the social dimension, the minimum sub-index value is scored by Libya 0.05 , Algeria 0.27 , Morocco 0.35 , and Tunisia 0.35 .

\subsection{Results of the Environmental Dimension Sub-Index}

Fig. 4(b) shows the result of the environmental subdimension and the contribution of each indicator selected in this dimension. Results reveal that Morocco 0.6, Mexico 0.59, Spain 0.56, and Algeria 0.55 are the countries that scored the highest value in the environmental dimension, mainly because those countries have the highest Average yearly direct Irradiation and the lowest GHG intensity and $\mathrm{CO}_{2}$ emissions.

\subsection{Results of the Technical Dimension Sub-Index}

The information stemming from Fig. 4(c) shows that Canada and the USA have the highest score in this dimension, 0.80 and 0.74 , mainly due to their high-technology exports and the high percentage of technicians in research and development in the population; also the countries have a large PV equivalent area comparing to the other studied countries in this research.

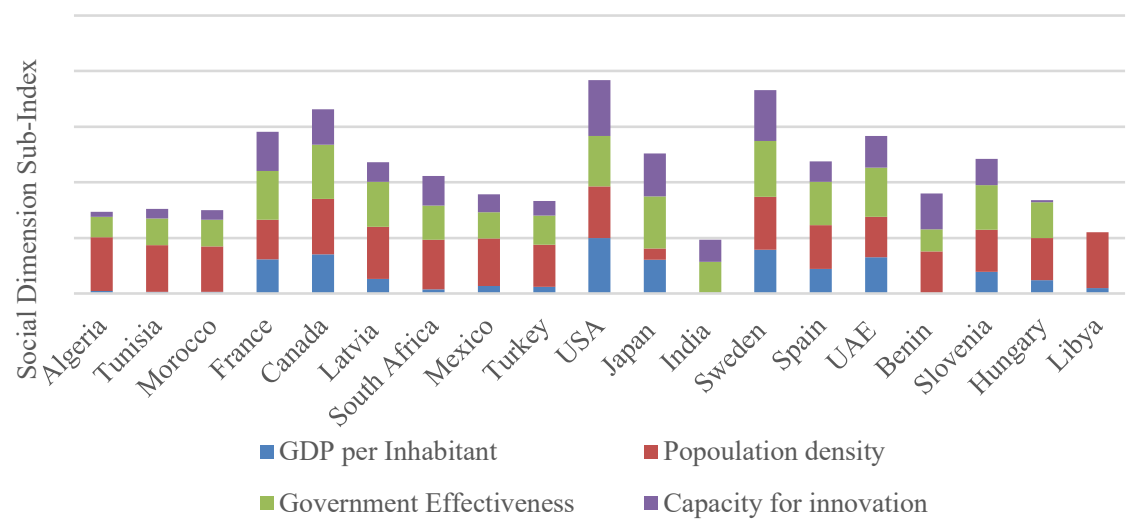

(a)

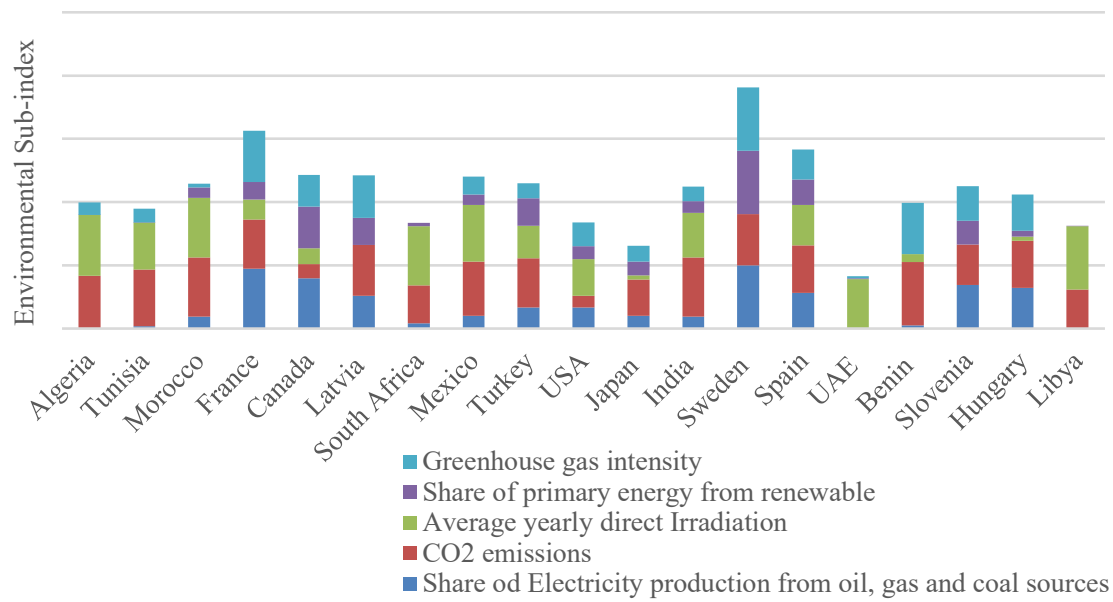

(b) 


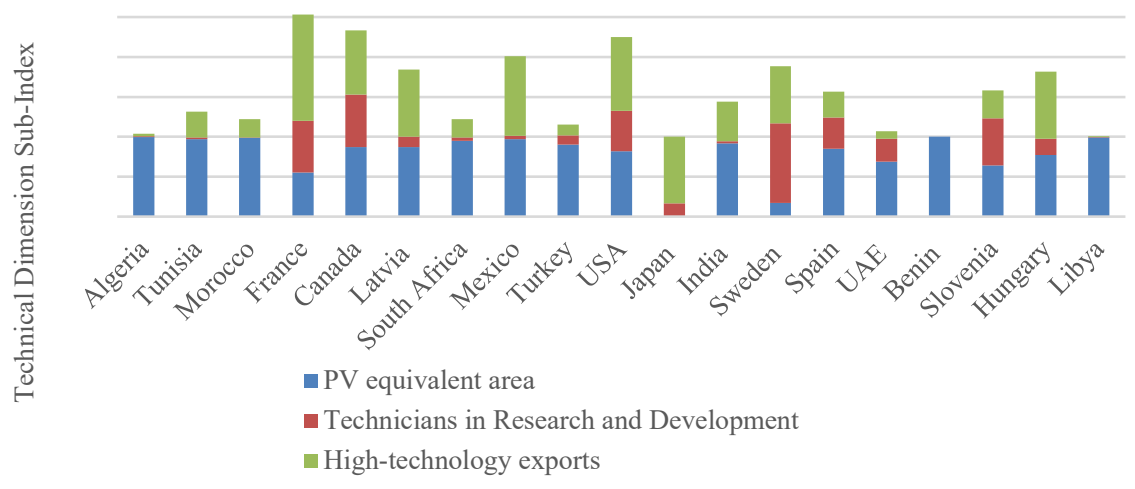

(c)

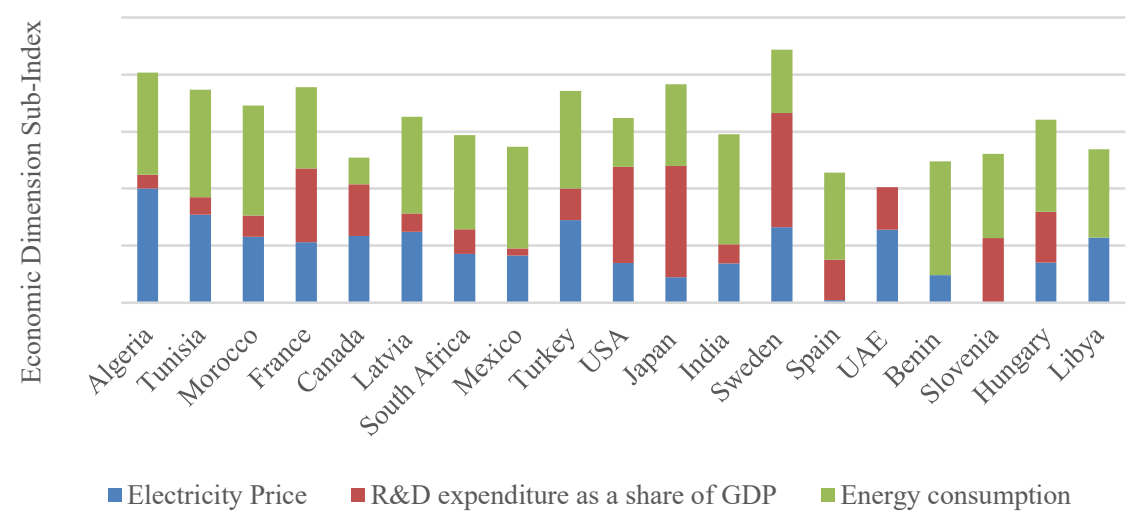

(d)

Fig. 4. a) Social Dimension Sub-Index; b) Environmental Sub-index; c) Technical Dimension Sub-Index; d) Economic Dimension Sub-Index.

\subsection{Results of the Economic Dimension Sub-Index}

Fig. 4(d) shows that Sweden, Japan, and USA have the highest value in the dimensions $0.89,0.79$, and 0.70 . Countries that scored a minimum in the economic dimension are Benin, Libya, and Mexico reaching a value of $0.14,0.19$, and 0.21 , respectively. We find a clear correlation of a lower score in the emerging countries in the factor of $R \& D$ expenditure as a share of GDP \%.

The results show that each of the studied countries presented strengths and weaknesses corresponding to different dimensions. The solar energy efficiency index gives a clear indication about the countries solar energy efficiency. Results show that the environmental dimension and precisely the factor of solar irradiation potential is not the main factor of reach solar energy efficiency. This study demonstrates that the technical dimension and social dimensions are the most critical factors with the highest contribution to the SEI with an average score of 0.6 and 0.56 .

Therefore, to achieve higher solar energy efficiency, emerging countries with a high solar irradiation potential need to develop and prioritize the technical and economic dimensions. It 
is recommended that the governments, urban planners, and policymakers consider all four dimensions for better solar energy efficiency and integration.

\section{CONClusion}

This paper provided an evaluation of solar energy efficiency by composite index. The SEI allows an evaluation of solar energy efficiency and performance across different countries; 19 countries over four continents were evaluated in this study for the year 2019 .

The construction of the SEI took into consideration 15 indicators grouped into four main dimensions: economic, environmental, social, and technical.

The results show that each of the studied countries presented strengths and weaknesses corresponding to different dimensions. The solar energy efficiency index gives a clear indication about the country's solar energy efficiency.

Results reveal that the technical dimension and social dimensions are essential factors for solar energy efficiency, as shown both dimensions have the highest contribution to the SEI with an average score of 0.6 and 0.56 . Therefore, to achieve higher solar energy efficiency, countries with a high solar irradiation potential need to develop and prioritize the technical and economic dimensions. It is recommended that the governments, urban planners, and policymakers consider all four dimensions for better solar energy efficiency and solar integration. This work's future scope includes more indicators from the environmental and technical dimensions s. Further, using different weights determination and normalization methods will be considered a part of future work.

\section{REFERENCES}

[1] Freudenberg M. Composite indicators of country performance: A Critical assessment. OECD Science, Technology and Industry working papers. Paris: OECD Publishing, 2003.

[2] Ang B. W., Choong W., Ng T. Energy security: Definitions, dimensions and indexes. Renewable and Sustainable Energy Reviews 2015:42:1077-1093. https://doi.org/10.1016/j.rser.2014.10.064

[3] Saisana M., Saltelli A. Uncertainty and sensitivity Analysis of the 2010 Environmental Performance Index. Luxembourg: Office for Official Publications of the European Communities, 2010.

[4] Brundtland G. H., et al. Our Common Future. New York: Oxford University Press, 1987.

[5] Matteo Mazziotta A. P. Methods for Constructing Composite Indices: One for All or All for One? The Italian Journal of Economic, Demographic and Statistical Studies 2016:82:394-411.

[6] Becker W., et al. Weights and importance in composite indicators: Closing the gap. Ecological Indicators 2017:80:1222. https://doi.org/10.1016/j.ecolind.2017.03.056

[7] Slišāne D., et al. Assessment of energy sustainability in statistical regions of Latvia using energy sustainability index. Environmental and Climate Technologies 2020:24(2):160-169. https://doi.org/10.2478/rtuect-2020-0063

[8] Castillo H., Pitfield D. E. ELASTIC - A methodological framework for identifying and selecting sustainable transport indicators. Transportation Research Part D: Transport and Environment 2010:15:179-188. https://doi.org/10.1016/j.trd.2009.09.002

[9] OLADE, ECLAC, GTZ. Energy and Sustainable Development in Latin America and the Caribbean: approaches to energy policy. Latin American Energy Organization (OLADE), 1997.

[10] Barrera-Roldán A., Saldívar-Valdés A. Proposal and application of a Sustainable Development Index. Ecological Indicators 2002:2(3):251-256. https://doi.org/10.1016/S1470-160X(02)00058-4

[11] Shah S. A. A., et al. Energy security and environmental sustainability index of South Asian countries: A composite index approach. Ecological Indicators 2019:106:105507. https://doi.org/10.1016/j.ecolind.2019.105507

[12] Saltelli A. Composite indicators between analysis and advocacy. Social indicators research 2007:81:65-77. https://doi.org/10.1007/s11205-006-0024-9

[13] Krajnc D., Glavič P. A model for integrated assessment of sustainable development. Resources, Conservation and Recycling 2005:43(2):189-208. https://doi.org/10.1016/S0921-3449(04)00120-X

[14] Mathiesen B. et al. Smart energy systems for coherent $100 \%$ renewable energy and transport solutions. Applied Energy 2015:145:139-154. https://doi.org/10.1016/j.apenergy.2015.01.075 
[15] Dolge K., Kubule A., Blumberga D. Composite index for energy efficiency evaluation of industrial sector: sub-sectoral comparison. Environmental and Sustainability Indicators 2020:8:100062. https://doi.org/10.1016/j.indic.2020.100062

[16] Ouma Y. O., Tateishi R. Urban flood vulnerability and risk mapping using integrated multi-parametric AHP and GIS: methodological overview and case study assessment. Water 2014:6(6):1515-1545. https://doi.org/10.3390/w6061515

[17] Neofytou H., Nikas A., Doukas H. Sustainable energy transition readiness: A multicriteria assessment index. Renewable and Sustainable Energy Reviews 2020:131:109988. https://doi.org/10.1016/j.rser.2020.109988

[18] Saaty, T. L. How to make a decision: the analytic hierarchy process. European Journal of Operational Research 1990:48(1):9-26. https://doi.org/10.1016/0377-2217(90)90057-I 